\title{
Theorizing Management Reforms in International Organizations
}

\author{
Christoph Knill and Michael W. Bauer
}

\section{Introduction}

The starting point for this volume is our still rather limited understanding of management reforms in international organizations, both in theoretical and empirical terms. These deficits are not only linked to a lack of investigations of management reforms in international organizations, but also emerge from the fact that little theoretical attempts have been made in order to link the findings from existing studies to broader and more general theories on organizational change and administrative reform. Against the backdrop of this constellation, it is the central objective of this concluding chapter to elaborate on the extent to which this gap can be addressed on the basis of the articles collected in this volume.

The articles within the present volume point indeed to some essential variables and relationships with respect to management reforms in international organizations. Building on the results of the case studies, we attempt to draw some tentative conclusions by formulating a number of crucial hypotheses that not just summarize the added value of our joint effort but bear - as we think - challenging questions as well as promising potential for further empirical and theoretical research in this area.

\section{The influence of external factors}

As a first group of factors which can trigger management reforms in international organizations, many studies in this book emphasized the relevance of external factors; i.e. influences that emerge from the broader organizational environment. In this respect two particular aspects have to be emphasized, namely effects of organizational domain and effects of a changing constituency.

\section{$2.1 \quad$ Organizational domain}

The findings presented in various case studies above indicate that the relevant organizational environment can have an important impact on the occurrence or nonoccurrence of management reforms. This causal relationship, however, goes beyond a mere mechanistic linkage of domain changes leading to respective organizational 
responses. Such an assumption would not only mean overlooking the fact that organizations might have considerable autonomy from their environment and are capable of shaping and affecting this environment (March/Olsen 1995). It also neglects - and this is the central argument we are able to deduct from the cases studies - the fact that specific characteristics of the organizational domain affect its influence on organizational change.

The evidence presented above indicates that the homogeneity of the organizational domain is of particular importance in this respect. It makes a difference whether an international organization fulfils very narrowly defined tasks within a rather homogeneous organizational environment or whether the organization is active in a variety of different sectors, implying that it operates within a much more heterogeneous domain. Modeling the relationship between an organization and its relevant environment in terms of a signal game, we expect an organization to receive clearer and less ambiguous signals (for example to reform in order to combat organizational deficits) if it operates in a homogenous domain than is the case for organizations operating in a more heterogeneous domain. In the latter case, it is well conceivable that organizations receive contradictory signals and hence remain more hesitant when deciding upon respective changes.

To illustrate this point, we might take the examples of the ECB, the European Commission as well as the OECD. The ECB has a single major task and operates in a professional environment of great homogeneity (as regards the efficiency-driven norms and concepts of the economic sector) in which management standards are generally undisputed and well accepted. As a result, it is hardly surprising that the ECB has undertaken considerable reform and hence responded to the rather clear signals from its domain. The European Commission and the OECD, by contrast, are responsible for a huge variety of outputs and hence are confronted with highly differentiated environments. Against this backdrop, it seems highly plausible that both organizations for many years have been (and in the OECD case still are) reform laggards. Based on these considerations, we can formulate the following hypotheses:

Hypothesis 1: The extent to which changes in the organizational domain trigger management reforms in international organizations depends on the degree of domain homogeneity. The more homogeneous the organizational environment, the more we expect far-reaching and swift organizational changes in order to close potential gaps to developments in the organizational domain.

Hypothesis 2: As domain heterogeneity can be expected to increase with the number of tasks for which an organization is responsible, management reforms should be more pronounced (greater speed, broader objectives) in single-purpose than in multi-purpose organizations at the international level.

In addition to characteristics of an organization's domain one might expect similar influences emerging from the nature of its constituency. Do the reform orientations 
and reform developments in the member states of an international organization make a difference in terms of management reforms? And does it make a difference, whether the member states reflect a rather homogenous group in terms socioeconomic and political conditions?

Interestingly, the evidence of the case studies in this book does not support these expectations. There seems to be no clear and straightforward linkage between constituency characteristics and organizational reform developments. For instance, reform developments in the ECB and the European Commission differ sharply, notwithstanding the fact that they have (almost) the same constituency. In addition, we find that the reform developments in the European Commission are still more pronounced than those within the OECD, although in the OECD there is a higher share of member states that can be classified as pioneer states of public management reforms (cf. also Knill/Balint 2008). We thus should have expected much more reform activity in the OECD than in the European Commission. These findings are rather surprising from the perspective of intergovernmentalist approaches (cf. Moravcsik 1993, 1998), which expect that international organizations are highly responsive to the interests of their members.

While the nature of the constituency as such therefore appears to be of limited relevance in order to account for the occurrence of management reforms in international organizations, the opposite is the case when it comes to changes in the constituency. Several case studies report strong increases in reform activities as a result of such changes. This holds true not only for respective developments in the Nordic Council (where membership decreased), but also for the European Commission and the European Parliament, where prospects of enlargement constituted an important driving force for managerial reforms.

In this context, however, it should be emphasized that constituency changes per se might only be seen as a necessary, but not sufficient condition for triggering reforms. As indicated by the case studies, increases or decreases in membership were typically linked to the perception among the member states of existing performance deficits that were expected to further increase with membership changes. These considerations suggest the following hypotheses on constituency effects:

Hypothesis 3: Characteristics of an international organization's constituency (in particular with regard to homogeneity of public management orientations and socioeconomic and political conditions) have no significant effect on the speed and scope of management reforms in this organization.

Hypothesis 4: The speed and scope of management reforms in international organizations increase with the extent to which pre-existing concerns on performance gaps coincide with changes in the organization's constituency.

\section{The influence of internal factors}

Whether or not international organizations change their internal management structures is also affected by factors that are endogenous to the organization in question, 
including the nature of an organization, its size, its leadership and internal politics as well as the internal origin of reform attempts.

\subsection{The nature of the organization}

It seems rather plausible that the nature of an organization, and here in particular its status as a supranational or intergovernmental body, has an impact on respective management reforms. This argument is based on the assumption that supranational organizations dispose of a higher degree of autonomy from their members than it is the case for their intergovernmental counterparts. As a consequence, we should expect a much higher responsiveness of intergovernmental organizations to changes in their member states' preferences, hence implying that the speed and degree of management reforms should be more pronounced than in supranational organizations.

This expectation, however, is not supported by the case studies in this book. On the contrary, we find rather comprehensive reform developments in the ECB, the European Parliament and - with some delay - also in the European Commission, while reforms at the level of the intergovernmental organizations investigated in this book altogether remained rather piecemeal and at least not more pronounced than those in the supranational bodies under study.

How can this puzzling finding be explained? We argue that our findings imply no contradiction to existing theories in which the degree of organizational autonomy is seen as important factor affecting the policy-making capacity and policy impact of international organizations. It is hardly disputed that a supranational organization, such as the European Commission, in contrast to intergovernmental national organizations enjoys a considerable degree of autonomy and hence independent influence on policy-making within the European Union. However, while autonomy might make an important difference for an organization's role in policy-making, this need not necessarily be the case when it comes to questions of internal operational autonomy and internal affairs. Here it is well conceivable that member states leave international organizations (regardless of their status as either supranational or intergovemmental body) rather broad leeway, as these issues do not directly interfere with domestic positional and policy interests.

Indeed our case studies underline that while the level of autonomy as regards policy delivery of international organizations might vary, virtually all organizations under study appear to be rather independent when it comes to the regulation of their internal administrative affairs. Hence, the supranational or intergovernmental nature of international organizations seems to be of limited relevance in order to account for the degree of reforms of their internal management.

Hypothesis 5: The nature of an international organization (in particular its status as supranational or intergovernmental body) has no significant effect on the speed and scope of management reforms in this organization. 
The case studies collected in this volume also provide evidence for the fact that the size of an international organization has an impact on the degree and process of management reforms. In this context, size is not only a matter of the number of staff per se (which can reach from some dozens to several thousand civil servants), but also closely related to the extent to which international organizations have been designed for single or multiple tasks.

More specifically, the smaller an organization is, the less we expect the organization to be able to independently influence its organizational environment. Rather, small organizations might be much more responsive to developments and challenges emerging in their domain. As a consequence, reforms in international organizations of small size are more likely to reflect the pattern of continuous incremental adaptations. The fact that smaller organizations with a rather limited spectrum of responsibilities are more responsive to their environment and more apt to respond to changing requirements with incremental but continuous internal reforms is well illustrated by the case of the Nordic Council.

For larger organizations, by contrast, reform patterns might reflect a less responsive pattern, assuming that these organizations either have a more autonomous position towards their environment as a result of their higher influence in their domain or that these huge bureaucratic entities are just less apt to adapt quickly to changing requirements. Their reform patterns will hence reveal a less continuous, but also less incremental pattern. As larger organizations can afford to leave a bigger gap between their own structures and their environment, reforms, when actually perceived as being necessary, are more likely to go beyond merely piecemeal adjustments. This can be expected at least in terms of reform rhetoric, leaving issues of deficient implementation aside.

Hypothesis 6: The smaller an international organization in terms of size, the more responsive it is to changes in its environment, implying that management reforms follow a pattern of continuous and incremental adjustments.

\subsection{Leadership and internal politics}

The adoption and implementation of organizational reforms requires a certain degree of consensus among the involved actors. This consensus, however, can hardly be expected to emerge 'out of the blue', as reforms, in many instances, are highly contested between potential reform beneficiaries and reform opponents seeking to preserve the status quo or favoring other reform options and directions.

Against this background, successful reformers not only require building coalitions for achieving necessary majorities in the decision-making process, but also have to ensure the compliance of important stakeholders during the implementation stage. Successful management reforms in international organizations are strongly dependent upon the strategic and tactical capabilities of their leadership in order to over- 
come internal resistance to change. In other words, internal reform processes matter for the magnitude of organizational reform. The design of these processes, on the other hand, is strongly affected by the existence of committed political entrepreneurs within the organization and their leadership skills. The relevance of this argument becomes apparent in almost all studies collected in this book, but is most pronounced and empirically demonstrated in the analysis by Baumann, Kobler and Hagel.

Hypothesis 7: Management reforms in international organizations are more intensive the more there is committed and skillful leadership within the organization.

\subsection{The impact of organizational crisis}

What is the impact of organizational crisis on the degree of respective management reforms? The evidence from our case studies indicates that there is no straightforward relationship between crisis perception and reform. This can be traced to three aspects.

First, while the existence of a crisis can be seen as important condition for reforms taking place, this does not automatically lead to actual adoption of respective reforms. There might still be powerful actors within the organization who successfully oppose reform proposals.

Second, it is well conceivable and often the case that organizations reform themselves in the absence of crisis. Change without crisis can either occur because organizations anticipate potential problems in the future or react to them already at an early stage. Moreover, change without crisis can occur as a result of isomorphic adjustments to developments in the organizational environment. In the case studies of this volume, we see organizations reform rarely in face of open crisis but rather in response to organizational changes within their peer group or as a pre-emptive measure in view of alternations in their environmental constellations. In other words, questions of organizational legitimacy are more important than issues of functional performance in order to bring about organizational change. This point is driven home by many case studies collected in this book; in particular by the chapters of Balint and Knill as well as Etzold, Kerler and Mehde.

Third, the link between crisis and reform is further complicated by the fact that the very nature of organizational crisis matters. As argued by Knill and Balint (2008), it makes a difference whether crisis stems from a kind of dissatisfaction with the performance of an international organization or whether it is the result of a search for a new organizational identity and mission. In case of performance challenge, one would expect management reforms to be seen as useful devices to improve the situation. Organizational identity crisis, by contrast, might have a paralyzing effect. Without a clear idea of the (future) mission of an organization reform momentum is lost; would-be reformers do not know with certainty what is most important to focus on and where to start improvement. 
Hypothesis 8: The extent to which the existence or perception of crises affects management reforms in international organizations depends on the nature of crisis. The more crises are linked to the organization's very identity (implying that its core functions are disputed) rather than mere operational performance gaps, the lesser the organization's capability of responding swiftly and comprehensively to the challenges. The more a crisis affects an organization's core, the lesser the likelihood that crisis actually triggers systematic reform endeavors.

\subsection{Political versus administrative reform origin}

A very fundamental dichotomy that might affect results, goals and processes of organizational reforms refers to the question whether organizational reforms are initiated predominantly by administrative actors or by political leaders within the organization in question. As political and administrative actors might pursue rather different reform objectives and be guided by rather different interests, it seems rather plausible that this distinction has an impact on the scope, scale and the very character of organizational reforms.

Administrative reformers appear concerned primarily with issues of functional performance. That implies that reforms dominated by the administration of an international organization are more directed towards incremental adjustments in order to improve and optimize the organization's operative capacities. If reforms are politically driven, by contrast, issues of legitimacy towards the organizational environment rather than aspects of functional performance might play a dominant role. Moreover, as politicians generally have an incentive to demonstrate a profound impact of their activities, they should strive for more fundamental rather than piecemeal developments. At the same time, however, the potential ignorance towards functional issues might imply that one-sided political reforms might suffer from far-reaching implementation problems if they are not supported by the administration. As a consequence, there is a higher potential that politically driven reforms instead remain at a symbolic level, with fundamental reform announcements being trimmed down to minor changes during the implementation stage. These considerations suggest the following hypotheses:

Hypothesis 9: The more management reforms of international organizations are dominated by administrative actors, the more we will observe incremental changes in order to improve functional performance. By contrast, the more reforms are driven by political actors, the higher the probability of more fundamental reform attempts in order to increase an organization's external legitimacy.

Hypothesis 10: The more political actors dominate management reforms of international organizations, the higher the likelihood of implementation deficits, given a gap between political legitimacy concerns and issues of functional performance advocated by the organization's administration. 


\section{Perspectives}

This volume on management reforms of international organizations reflects an explorative exercise. The particular conclusions of the individual case studies and also the general hypotheses in this final chapter are first attempts to gather facts, systematize observable patterns and propose candidate explanations. In other words, our results are the starting point for a discussion rather than a synthesis to settle competing claims and theories. Keeping these limitations in mind, this volume raises some important questions and offers potential answers to them.

Moreover, the analyses collected in this volume are based on detailed case studies, which take considerable effort in a thick description of empirical developments. The latter aspect per se constitutes an important achievement, given the dearth of either empirical studies or theoretical approaches that tackle the issue of management reforms in international organizations. In view of the explorative character underlying this book, it seems appropriate to end with four recommendations as to where - in our opinion - researchers interested in the topic may want to go and what they should keep in mind in order to further improve our knowledge about management reforms of international organizations.

(1) Invest in good description. First and above all, we need more reliable empirical data on the phenomenon of management reforms in international organizations. There is an unjustified disdain in contemporary social science for the description of political events. While the primary aim of social sciences is to uncover causal inferences, we should not forget that causal explanations have to be based on sufficient and adequate description. However, with respect to explaining management reforms in international organizations we still do not know enough about our factual and potential cases for developing already well-specified concepts and general explanations. In particular, we need better tools for evaluating the intensity of management reforms in international organizations. Furthermore, we need to know more about the various elements of management reforms (financial-budgetary, personnel and institutional) and their respective importance for organizational change on the whole. We thus need to work on ways to optimize our categories of change and on exact operationalizations as to relate observations more precisely to our theoretical concepts. Good description is an indispensable requirement for the development of sound theories.

(2) Focus the actors. A further challenge is to connect macro-level reform change with micro-level behavior of real world human actors. Our understanding of individual actors' preferences, their utility functions but also the implications of culturally or nationally bound behavioral patterns is still very limited. For example, it may be that culture and nationality are no significant factors since such differences are business as usual for transnational administrative elite like the cosmopolitically educated and socialized work force of international organizations. However, the case studies suggest that reform promoters often have a background of a particular administrative reform culture through their experience in their 'home country'. In fact we know little about whether and to what extent particular role understanding, or 
images of political order, particular career paths (predominant national or international socialization), particular patterns of staff representation and unionization, flexible or rigid career structures actually affect management reforms in international organization.

(3) Encourage dialogue between the sub-disciplines. It would be a huge mistake to analyze management reforms in international organizations only from the perspective of distinctive academic sub-disciplines. Rather the challenge is to identify common ground and to combine tools, theories and explanations from the various related sub-disciplines (public administration, international relations, organization theory, political science).

(4) Finally, we encourage researchers intending to explore the field of management reforms of international organizations not to lose sight to the 'so what' question. In other words, we should not stop at describing and explaining management reforms as the dependent variable. It is rather an important step of further research to take management reforms of international organizations as the independent variable and ask what difference particular patterns of reforms make for policy output and policy outcomes (Bauer 2008). If we know more about these relationships, the discussion of management reforms of international organization can be fruitfully linked to questions of policy-making under the conditions of multilevel governance that are of crucial importance for policy-analysts, organizational sociologists, scholars of international relations as well as professionals and politicians.

In view of these future challenges for the study of management reforms in international organizations, we hope that this volume constitutes a useful point of departure for all who have a professional or an academic interest in the topic of management reforms of international organization - be it on understanding and managing organizational change or driven by detecting causes and effects of policy changes in multi-tiered political systems which are increasingly permeated by international organizations. 